\title{
INVENTARISASI TUMBUHAN PAKU (PTERIDOPHYTA) DI SOPOTINJAK TAMAN NASIONAL BATANG GADIS (TNBG) KABUPATEN MANDAILING NATAL
}

\section{Dwi Ratna Anjaning Kusuma Marpaung}

\author{
Program Studi Pendidikan Biologi, Fakultas Pendidikan MIPA, Institut Pendidikan Tapanuli Selatan \\ email: dwiraakm@gmail.com
}

\begin{abstract}
The Sopotinjak area of the Batang Gadis national park is one of the conservation areas that does not yet have information about the types of ferns. This research was conducted April 2017 using survey method and identify in the laboratory. The inventory results obtained 17 types of fern are Abrodictyum caudatum (Brack.) Ebihara \& K. Iwats., Alsophila cuspidata (Kunze) D.S. Conant, Arachniodes sp., Asplenium serratum L., Didymochlaena trunculata (Sw.) J. Sm, Diplazium sp., Goniophlebium persicifolium (Desv.) Bedd., Goniophlebium sp., Lindsaea sp., Microsorum sp., Nephrolepis exaltata (L.) Schott, Nephrolepis sp., Prosaptia sp., Selaginella martensii Spring., Selaginella sp., Selaginella wildenowii (Desv. \& Baker) dan Vittaria elongata Sw. and belonging to 2 divisions, 2 classes and 12 families are Aspidiaceae, Aspleniaceae, Athyriaceae, Cyatheaceae, Dryopteridaceae, Grammitidaceae, Hymenophyllaceae, Lindsaeaceae, Nephrolepidaceae, Polypodiaceae, Vittariaceae and Selaginellaceae. Polypodiaceae and Selaginellaceae are the family with the highest number of species, each of which is 3 types. Polypodiaceae includes Goniophlebium persicifolium (Desv.) Bedd., Goniophlebium sp. and Microsorum sp., while Selaginellaceae includes Selaginella martensii Spring., Selaginella wildenowii (Desv. \& Baker) and Selaginella sp..
\end{abstract}

Keywords: Inventory, Fern, Pteridophyta, Sopotinjak, TNBG.

\begin{abstract}
Abstrak
Kawasan Sopotinjak Taman Nasional Batang Gadis merupakan salah satu kawasan konservasi yang belum memiliki informasi mengenai jenis-jenis dari tumbuhan paku (Pteriophyta). Penelitian ini telah dilakukan pada bulan April 2017 dengan menggunakan metode jelajah dan identifikasi di laboratorium. Hasil inventarisasi diperoleh 17 jenis tumbuhan paku yaitu Abrodictyum caudatum (Brack.) Ebihara \& K. Iwats., Alsophila cuspidata (Kunze) D.S. Conant, Arachniodes sp., Asplenium serratum L., Didymochlaena trunculata (Sw.) J. Sm, Diplazium sp., Goniophlebium persicifolium (Desv.) Bedd., Goniophlebium sp., Lindsaea sp., Microsorum sp., Nephrolepis exaltata (L.) Schott, Nephrolepis sp., Prosaptia sp., Selaginella martensii Spring., Selaginella sp., Selaginella wildenowii (Desv. \& Baker) dan Vittaria elongata Sw. dan tergolong ke dalam 2 divisi, 2 kelas dan 12 famili yaitu Aspidiaceae, Aspleniaceae, Athyriaceae, Cyatheaceae, Dryopteridaceae, Grammitidaceae, Hymenophyllaceae, Lindsaeaceae, Nephrolepidaceae, Polypodiaceae, Vittariaceae dan Selaginellaceae. Polypodiaceae dan Selaginellaceae merupakan famili dengan jumlah jenis tertinggi yaitu masing-masing sebanyak 3 jenis. Polypodiaceae meliputi jenis Goniophlebium persicifolium (Desv.) Bedd., Goniophlebium sp. dan Microsorum sp.. Sedangkan Selaginellaceae meliputi jenis Selaginella martensii Spring., Selaginella wildenowii (Desv. \& Baker) dan Selaginella sp..
\end{abstract}

Kata Kunci: Inventarisasi, Tumbuhan paku, Pteridophyta, Sopotinjak, TNBG. 


\section{PENDAHULUAN}

Taman Nasional merupakan salah satu bentuk hutan konservasi yang bertujuan untuk meningkatkan fungsi perlindungan sistem penyangga kehidupan, pengawetan keanekaragaman jenis tumbuhan dan satwa, serta pemanfaatan secara lestari sumber daya hayati dan ekosistemnya dari kawasan hutan alam yang dapat dikelola dengan sistem zonasi. Taman Nasional Batang Gadis (TNBG) adalah taman nasional ke-42 yang masih tersisa di Pulau Sumatera yang memiliki biodiversitas melimpah berdasarkan keputusan Menteri Kehutanan No. 126/Menhut-II/2004.

TNBG terletak di pegunungan Bukit Barisan Sumatera bagian utara. Secara administrasi berlokasi di kabupaten Mandailing Natal dan merupakan hamparan hutan mulai dari hutan rawa dataran tinggi, lahan basah, lembah sungai, hutan gamping, hutan dataran rendah perbukitan sampai hutan pegunungan dengan ketinggian antara 300-2.145 m dari permukaan laut. Curah hujan rata-rata tahunan di TNBG sekitar 1.717,5 mmth dengan rata-rata hari hujan per bulan adalah 12-13 hari sehingga termasuk dalam tipe A (Schmidt dan Ferguson, 1951). Suhu rata-rata bulanan adalah $23-25,4^{\circ} \mathrm{C}$ dengan valensi rata-rata bulannya tidak begitu besar karena dipengaruhi oleh ketinggian tempat/altitude (Balai KSDA Sumatera Utara II, 2005).

TNBG memiliki arti strategis secara lokal, nasional dan global dengan kandungan keanekaragaman baik hayati maupun non hayati dan potensi sumber daya alam serta jasa-jasa lingkungan yang sangat kaya yang memberi daya tarik berbagai pihak untuk memanfaatkannya. Tumbuhan paku (Pteridophyta) merupakan salah satu potensi sumber daya alam khususnya flora yang ditemukan di kawasan TNBG. Tumbuhan paku atau Pteridophyta berasal dari bahasa Yunani diambil dari kata pteris berarti "sayap atau bulu” dan phyta yang berarti "tumbuhan". Tumbuhan paku merupakan suatu divisi yang warganya berupa tumbuhan kormus yang artinya tubuhnya dengan nyata dapat dibedakan dalam tiga bagian pokoknya yaitu akar, batang dan daun. Namun demikian pada tumbuhan paku belum dihasilkan biji. Perkembangbiakannya dengan spora dan bentuk morfologi tumbuhan paku bermacam-macam yaitu sesuai dengan adaptasi.

Tumbuhan paku merupakan tumbuhan kosmpolitan yang dapat hidup dimana saja. Menurut Loveless (1989) bahwa tumbuhan paku dapat tersebar luas mulai daerah tropis hingga dekat kutub utara dan selatan. Mulai dari hutan primer, hutan sekunder, alam terbuka, dataran rendah hingga dataran tinggi, lingkungan yang lembab, basah, rindang, kebun tanaman serta pinggir jalan juga tumbuhan paku dapat ditemukan. Menurut Ewusie (1990), kelimpahan dan penyebaran tumbuhan paku sangat tinggi terutama di daerah hutan tropis. Tumbuhan paku juga banyak terdapat di hutan pegunungan.

Tumbuhan paku diperkirakan mencapai sekitar 11.000 jenis. Kepulauan Indonesia diperkirakan memiliki koleksi tumbuhan paku tidak kurang dari 1.300 jenis (Raven et al., 1992 dalam Jamsuri, 2007). Dibandingkan dengan tumbuhan lain, tumbuhan paku masih kurang mendapat perhatian karena tumbuhan ini dianggap kurang memberikan manfaat yang berarti bagi kehidupan. Kehadiran tumbuhan paku secara tidak langsung memberikan manfaat dalam keseimbangan ekosistem antara lain dalam proses pembentukan tanah, pengamanan tanah akan erosi serta membantu proses pelapukan serasah hutan. Selain itu, manusia juga telah banyak memanfaatkan tumbuhan paku sebagai tanaman hias, sayuran dan bahan obat-obatan.

Menurut Polunin (1994) dalam Widhiastuti (2006) beberapa jenis Lycopodinae yang suka panas digunakan sebagai tanaman hias dalam pot dan paku kawat yang merayap digunakan dalam pembuatan karangan bunga. Pada beberapa jenis tumbuhan paku dapat dimanfaatkan sebagai sayuran seperti Diplazium esculentum (paku sayur), Aspedium repandum (paku tikus). Dalam hal untuk pengobatan jenis tumbuhan yang banyak dimanfaatkan adalah Selaginella plana (paku rane) digunakan sebagai pembersih darah dan Equisetum debile (paku ekor kuda) digunakan sebagai obat analgesik. Dalam bidang pertanian, Azolla pinnata (paku 
air) yang bersimbiosis dengan Anabaena (gangang hijau) digunakan untuk meningkatkan kesuburan tanah dengan cara mengikat nitrogen bebas dari udara (Heyne, 1987; Ogata et al., 1985 dalam Jamsuri, 2007).

Kurangnya informasi mengenai jenis-jenis tumbuhan paku di kawasan Sopotinjak, Taman Nasional Batang Gadis (TNBG) ini menjadi tantangan untuk dilakukannya inventarisasi terkait. Hasil dari penelitian ini diharapkan menambahkan database keanekaragaman tumbuhan khususnya tumbuhan paku (Pteridpohyta) di lokasi tersebut.

\section{METODE}

\section{Lokasi dan Waktu}

Lokasi penelitian inventarisasi tumbuhan paku (Pteridophyta) berada pada kawasan Taman Nasional Batang Gadis, Sopotinjak, Kecamatan Batang Natal, Kabupaten Mandailing Natal dan laboratorium Biologi, program studi pendidikan Biologi, fakultas pendidikan MIPA, Institut Pendidikan Tapanuli Selatan. Penelitian ini telah dilaksanakan pada bulan April 2017. Peta lokasi penelitian disajikan pada Gambar 1.

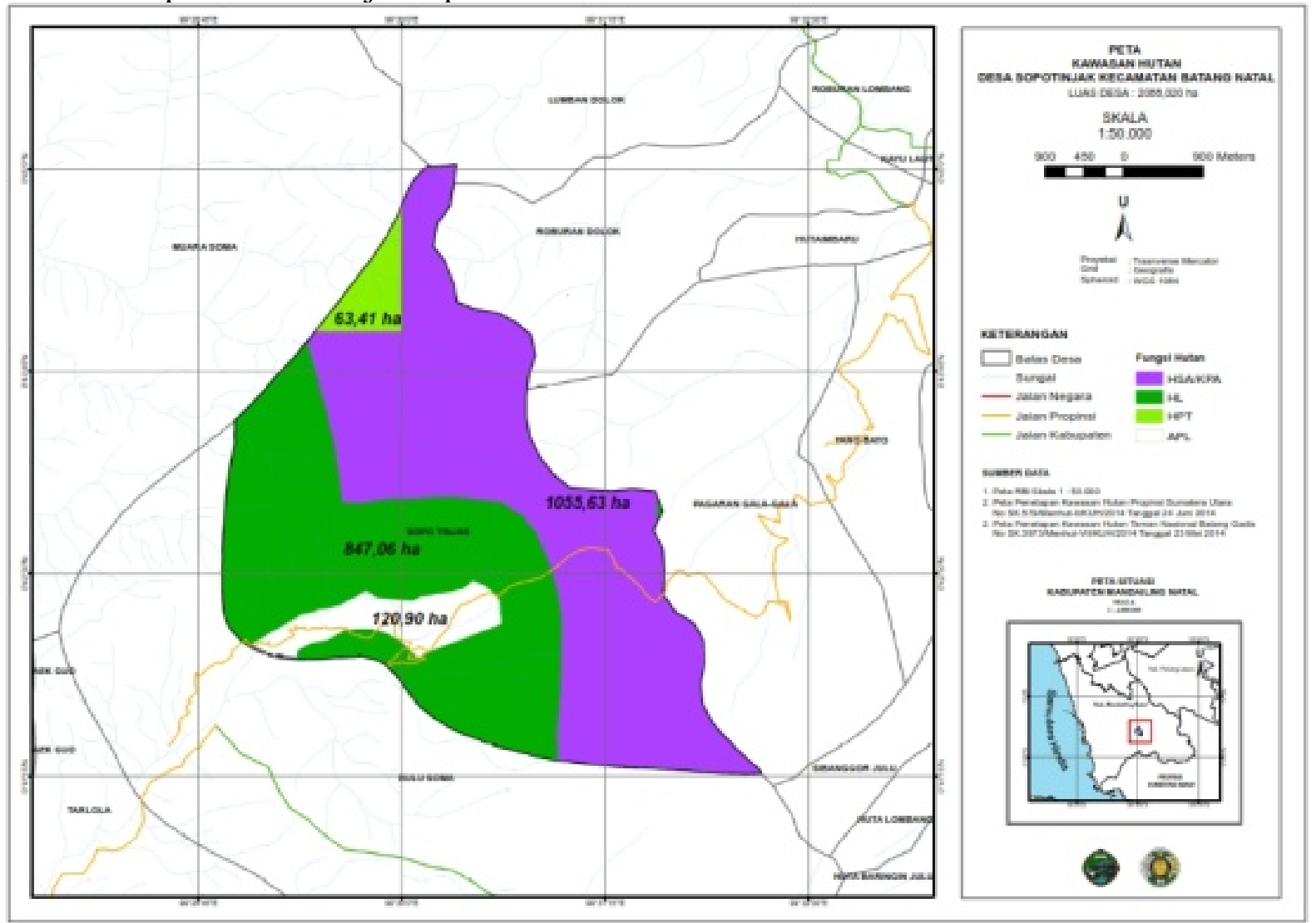

Gambar 1. Peta Kawasan Sopotinjak TNBG (Sumber: Balai TNBG)

\section{Prosedur Penelitian}

Inventarisasi tumbuhan paku (Pteridophyta) dilakukan dengan menggunakan metode survei di sepanjang jalur pengamatan dengan mengumpulkan sebanyak-banyaknya informasi jenis tumbuhan paku yang dijumpai di jalur pengamatan. Semua jenis tumbuhan paku yang ditemukan dilakukan pengamatan karakter morfologi dan dilakukan pengoleksian spesimen secara lengkap untuk dibuat herbarium kering guna kepentingan identifikasi jenisnya. Identifikasi jenis tumbuhan paku dilakukan di laboratorium biologi, program studi pendidikan Biologi, fakultas pendidikan MIPA, Institut Pendidikan Tapanuli Selatan. Data yang diproleh selanjutnya dianalisis secara deksriptif dan disajikan dalam bentuk tabel dan gambar. 


\section{HASIL DAN PEMBAHASAN}

Berdasarkan hasil inventarisasi yang telah dilakukan diperoleh 17 jenis tumbuhan paku (Pteridophyta) di Sopotinjak TNBG yang termasuk ke dalam 2 divisi, 2 kelas dan 12 famili seperti tercantum pada Tabel 1.

Tabel 1. Jenis-jenis Tumbuhan Paku (Pteridophyta) di Sopotinjak, Taman Nasional Batang Gadis, Kabupaten Mandailing Natal.

\begin{tabular}{|c|c|c|c|}
\hline \multicolumn{4}{|c|}{ Divisi Lycophyta } \\
\hline No & Kelas & Famili & Spesies \\
\hline 1 & \multirow{3}{*}{ Lycopsida } & \multirow{3}{*}{ Selaginellaceae } & Selaginella martensii Spring. \\
\hline 2 & & & Selaginella wildenowii (Desv. \& Baker) \\
\hline 3 & & & Selaginella sp. \\
\hline \multicolumn{4}{|c|}{ Divisi Pteridophyta } \\
\hline 4 & \multirow{14}{*}{ Polypodiopsida } & Aspidiaceae & Didymochlaena trunculata (Sw.) J. Sm \\
\hline 5 & & Aspleniaceae & Asplenium serratum $\mathbf{L}$. \\
\hline 6 & & Athyriaceae & Diplazium sp. \\
\hline 7 & & Cyatheaceae & Alsophila cuspidata (Kunze) D.S. Conant \\
\hline 8 & & Dryopteridaceae & Arachniodes sp. \\
\hline 9 & & Grammitidaceae & Prosaptia sp. \\
\hline 10 & & Hymenophyllaceae & $\begin{array}{l}\text { Abrodictyum caudatum (Brack.) Ebihara \& } \\
\text { K. Iwats. }\end{array}$ \\
\hline 11 & & Lindsaeaceae & Lindsaea sp. \\
\hline 12 & & \multirow{2}{*}{ Nephrolepidaceae } & Nephrolepis exaltata (L.) Schott \\
\hline 13 & & & Nephrolepis sp. \\
\hline 14 & & \multirow{3}{*}{ Polypodiaceae } & Goniophlebium persicifolium (Desv.) Bedd. \\
\hline 15 & & & Goniophlebium sp. \\
\hline 16 & & & Microsorum sp. \\
\hline 17 & & Vittariaceae & Vittaria elongata $\mathbf{S w}$. \\
\hline
\end{tabular}

Menurut Smith, et.al. (2006), tumbuhan paku digolongkan ke dalam 2 divisi utama yaitu Lycophyta dan Pteridophyta. Lycophyta merupakan tumbuhan berpembuluh yang pertama kali terpisah dari yang lain dan terdiri dari 1 kelas yaitu Lycopsida. Divisi Pteridophya terdiri dari 4 kelas monofiletik yaitu Psilotopsida, Equisetopsida, Marattiopsida dan Polypodiopsida (Pteridopsida, Filicopsida).

Berdasarkan Tabel 1 juga dapat diketahui bahwa famili tumbuhan paku yang memiliki jumlah jenis tertinggi adalah famili Polypodiaceae dan Selaginellaceae yaitu masing-masing terdiri dari 3 jenis. Polypodiaceae meliputi jenis Goniophlebium persicifolium (Desv.) Bedd., Goniophlebium sp. dan Microsorum sp.. Sedangkan Selaginellaceae meliputi jenis Selaginella martensii Spring., Selaginella wildenowii (Desv. \& Baker) dan Selaginella sp.. Hasil penelitian Daryanti (2009) juga menunjukkan bahwa famili Polypodiaceae dan Selaginellaceae merupakan famili yang paling banyak ditemukan.

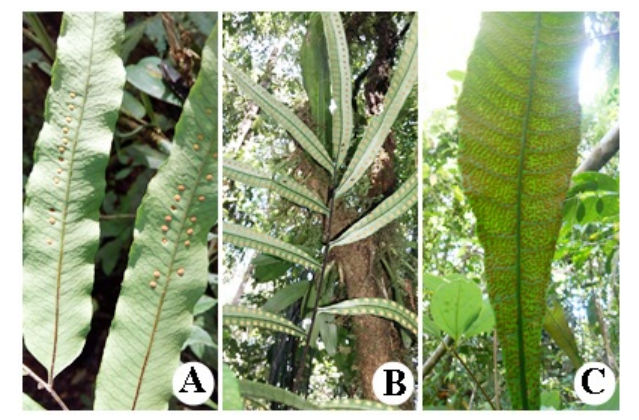

Gambar 2. Jenis-jenis dari famili Polypodiaceae A. Goniophlebium persicifolium (Desv.) Bedd., B. Goniophlebium sp. dan C. Microsorum sp.. 


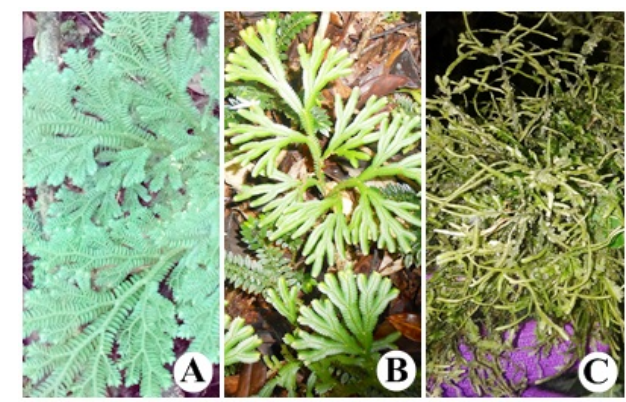

\section{Gambar 3. Jenis-jenis dari famili Selaginellaceae A. Selaginella martensii Spring., B. Selaginella wildenowii (Desv. \& Baker) dan C. Selaginella sp..}

Bukit I diperoleh famili dengan jumlah jenis yang paling banyak pada famili Selaginellaceae, Polypodiaceae dan Thelipteridaceae masing-masing sebanyak 2 jenis. Pada bukit II, jumlah famili terbanyak adalah famili Polypodiaceae sebanyak 2 jenis. Pada bukit III jumlah famili terbanyak adalah Polypodiaceae dan Atheriaceae masing-masing sebanyak 3 jenis diikuti oleh famili Selaginellaceae sebanyak 2 jenis. Pada bukit IV jumlah famili terbesar adalah Selaginellaceae sebanyak 3 jenis, famili Aspidiaceae dan famili Aspleniaceae masingmasing sbanyak 2 jenis. Pada bukit V jumlah famili terbanyak adalah famili Athyriaceae sebanyak 3 jenis.

Banyaknya jenis dari famili Polypodiaceae dan Selaginellaceae pada lokasi disebabkan kondisi faktor fisik yang sesuai bagi perkembangan dan keberlangsungan hidup jenis tumbuhan paku tersebut. Menurut LIPI (1980), paku di hutan umumnya merupakan paku yang menyukai naungan. Paku di hutan terlindung dari panas dan angin kencang. Di hutan tertutup ditandai dengan intensitas cahaya yang kurang dan kelembaban yang tinggi.

Hasil pengukuran di lokasi menunjukkan kelembaban tinggi berkisar 80-91\%, suhu berkisar 22-27 ${ }^{\circ} \mathrm{C}$ dengan ketinggian $>1.200$ mdpl. Lawrence (1958) menyatakan bahwa famili Polypodiaceae merupakan famili dari tumbuhan paku yang paling banyak jumlahnya yaitu sekitar 170 genus dan 7000 jenis yang tersebar di seluruh dunia. Sastrapradja et al., (2002) menyatakan bahwa Selaginellaceae dapat tumbuh baik di tempat yang lembab dengan ketinggian 400-1800 mdpl.

\section{KESIMPULAN}

Berdasarkan hasil inventarisasi tumbuhan paku (Pteridophyta) di Sopotinjak, Taman Nasional Batang Gadis (TNBG) ditemukan 17 jenis tumbuhan paku yaitu Abrodictyum caudatum (Brack.) Ebihara \& K. Iwats., Alsophila cuspidata (Kunze) D.S. Conant, Arachniodes sp., Asplenium serratum L., Didymochlaena trunculata (Sw.) J. Sm, Diplazium sp., Goniophlebium persicifolium (Desv.) Bedd., Goniophlebium sp., Lindsaea sp., Microsorum sp., Nephrolepis exaltata (L.) Schott, Nephrolepis sp., Prosaptia sp., Selaginella martensii Spring., Selaginella sp., Selaginella wildenowii (Desv. \& Baker) dan Vittaria elongata Sw..Tumbuhan paku (Pteridophyta) yang diperoleh dikelompokkan menjadi 12 famili yaitu Aspidiaceae, Aspleniaceae, Athyriaceae, Cyatheaceae, Dryopteridaceae, Grammitidaceae, Hymenophyllaceae, Lindsaeaceae, Nephrolepidaceae, Polypodiaceae, Vittariaceae dan Selaginellaceae. Polypodiaceae dan Selaginellaceae merupakan famili dengan jumlah jenis tertinggi.

\section{UCAPAN TERIMA KASIH}

Peneliti sangat berterima kasih kepada Balai Taman Nasional Batang Gadis (TNBG) yang telah memberikan izin untuk memasuki kawasan TNBG. 


\section{DAFTAR PUSTAKA}

Balai Konservasi Sumberdaya Alam II Sumatera Utara. 2005. Rencana Pengelolaan Taman Nasional Batang Gadis, Kabupaten Mandailing Natal, Provinsi Sumatera Utara 20062025. Direktorat Jenderal Perlindungan Hutan dan Konservasi Alam. Departemen Kehutanan. Medan.

Daryanti. 2009. Keanekaragaman Paku-Pakuan Teresterial Di Taman Wisata Alam Deleng Lancuk Kabupaten Karo. Tesis. Sekolah Pascasarjana, Universitas Sumatera Utara. Medan.

Departemen Kehutanan. 2004. Keputusan Menteri Kehutanan No. 126/ Menhut-II/ 2004 tentang Penunjukkan Taman Nasional Batang Gadis di Kabupaten Mandailing Natal, tanggal 29 April 2004. Departemen Kehutanan. Jakarta.

Ewusie, J.Y. 1990. Pengantar Ekologi Tropika. Penerjemah Usman Tanuwidjaya. Penerbit ITB. Bandung. Hlm. 249, 273.

Heyne, K. 1987. Tumbuhan Berguna Indonesia. Jilid 1. Koperasi Karyawan Departemen Kehutanan Republic Indonesia. Jakarta. Hlm. 78-93.

Jamsuri. 2007. Keanekaragaman Tumbuhan Paku Di Sekitar Curug Cikaracak, Bogor, Jawa Barat. Skripsi. Program Sudi Biologi, Jurusan MIPA, Fakultas Sains dan Teknologi, Universitas Islam Negeri Syarif Hidayatullah. Jakarta.

Lawrence, G.H.M. 1958. Taxonomy of Vascular Plants. The Macmillan Company: New York. LIPI. 1980. Jenis-Jenis Paku di Indonesia. Lembaga Biologi Nasional. LIPI. Bogor.

Loveless, A.R. 1989. Prinsip-Prinsip Ekologi dan Organisasi Ekosistem, Komunitas dan Lingkungan. Edisi Kedua. Penerbit Bumi Aksara. Jakarta. Hlm. 92-94.

Ogata, et al. 1985. Medical Herb Index Indonesia. Second Edition. P.T. Eisai Indonesia.

Polunin, N. 1994. Pengantar Geografi Tumbuhan dan Beberapa Ilmu Serumpun. Penerjemah: Prof. Ir. Gembong Tjitrosoepomo. Gadjah Mada University Press. Yogyakarta. Hlm. 531.

Raven, P.H., R.F. Evert and S.E. Eichorn. 1992. Biology of Plant. Worth Publiher. New York. P 343-353

Sastrapradja, S., J.J. Afriastini., D. Darnaedi and E.A. Widjaja. 2002. Jenis Paku Indonesia. Lembaga Biologi Nasional - LIPI. Bogor. Hlm. 129.

Smith, R., Pryer, M., Schuettpelz, E., Korall, P., Schneider, H dan Wolf, G. 2006. A Classification for Extant Ferns. Taxon. Vol. 55, No. 3, 705-731.

Widhiastuti, R., T. Alief Aththorick dan Wina Dyah Puspita Sari. 2006. Struktur dan Komposisi Tumbuhan Paku-Pakuan Di Kawasan Hutan Gunung Sinabung Kabupaten Karo. Jurnal Biologi Sumatera. Vol. 138 No. 2. 